\title{
The Phenotypic Effect of Cardamom oil on the Developmental Stages of Drosophila Melanogaster
}

\author{
Dr. Y. D. Akhare, H. A. Patharikar \\ Department of Zoology, Vidya Bharati Mahavidyalaya, C. K. Naidu Road, Camp. Amravati, Maharashtra, India
}

\begin{abstract}
Article Info

Volume 8, Issue 5

Page Number : 225-231

Publication Issue

September-October-2021

Article History

Accepted : 20 Sep 2021

Published : 30 Sep 2021

The fruit fly Drosophila melanogaster has been extensively studied as a model organism for genetic investigation. It also has many characteristics which make it an ideal organism for the study of animal development and behaviour, neurobiology and human genetic disease and condition. Drosophila melanogaster share several basic biological and chemical neurological and physiological similarities with mammals. In the present study, we noted the phenotypic effect of cardamom oil on the different stages of Drosophila melanogaster. The fruit flies were grown on 10-gram culture media supplemented with different concentration of cardamom oil $(0.5 \mu \mathrm{l}, 1 \mu \mathrm{l}, 2.5 \mu \mathrm{l})$. Further, the size and growth of different life stages of Drosophila melanogaster were observed and total protein estimated from it.The increase in the size and protein concentration in different life stages of controlled Drosophila melanogaster were recorded. Cardamom is a highly valued herbal spice used in tropical and subtropical Asia. cardamom is used as a flavouring and cooking spices in both food and drink and as a medicine.

Keyword: Drosophila Melanogaster, Cardamom Oil, Herbal Spice, Culture Media, Larval Stages, Protein
\end{abstract}

\section{INTRODUCTION}

Spices were among the most valuable items of trade in ancient and medieval times. As long ago as $3500 \mathrm{BC}$ the ancient Egyptians were using various spices for flavouring food, in cosmetics, and for embalming their dead. The use of spices spread through the Middle East to the Eastern Mediterranean and Europe. Today, it is available in most tropical places in Asia, including India, China, Bhutan, Vietnam, Malaysia, Korea, and Japan. In botanical terms, it belongs to the family of Zingiberaceae and its scientific name is Elettaria cardamomum. There are two main types or subspecies of cardamom. Their scientific names are Elettaria, which is called green or true cardamom, and Amomum, which stands for black white, or red cardamom (Nair KPP 2002). Cardamom has digestive, antispasmodic, carminative, anti-inflammatory, antimicrobial, aphrodisiac and diuretic properties.

Drosophila melanogaster, also known as the fruit fly, is an excellent model organism widely used in biological research that has made significant contributions to the greater scientific community over the lost century. It is because fruit flies are inexpensive to maintain in the laboratory, have 
simplified genetics, and short generation times allow for quick experiments with high sample numbers. Drosophila melanogaster exhibits complete metamorphism, meaning the life cycle includes an egg, larval forms, pupa and finally emergence as a flying adults. Eco-friendly and easily biodegradable plant products with natural insecticidal activity has increased in recent years. To control pests without disturbing the environment, natural products have been screened for potential sources of insecticides. Plant materials with insecticidal properties have been employed to kill insects all over the world for generations. These materials are considered to be an alternative to conventional pesticides owing to their low toxicity to warm-blooded mammals, in addition to their high volatility. Botanical insecticides may be safer for the environment than synthetic insecticides, and they are usually easily processed and utilized by farmers and small industries (Belmain et al., 2001). The cardamom, Elettaria cardamomum (L.) Maton (Zingiberaceae), as also known as the "Queen of spices", is a tall, perennial, reed-like herb growing wild. Some studies have shown that cardamom essential oils have inhibitory effects against fungus growth (Utta-Ur' et al., 2000), insecticidal activity (Abbasipour et al., 2011b) and marked antiapamodic, analgesic, as well as anti-inflammatory activity (AlZuhair et al., 1996). This study aims to investigate the effect of Cardamom Oil on the developmental stages of Drosophila melanogaster.

\section{MATERIAL AND METHODS}

Fruit flies were collected on ripe banana fruit. After that flies were cultured on potato, dextrose and agar culture media. Cardamom oil has monoterpenes, vitamins and minerals.

Preparation of culture media: Boil the potato and clean it then weight up to $100 \mathrm{gm}$ then add $1.09 \mathrm{gm}$ agar, $100 \mathrm{ml}$ of $\mathrm{H}_{2} \mathrm{O}$ added in it and $1 \mathrm{gm}$ dextrose. Homogenize the mixture and make a fine paste. After the formation of paste, autoclave it at $15 \mathrm{lb}$ for 10-15 min. Cool the media up to $60^{\circ} \mathrm{C}$. Then add $0.8 \mathrm{ml}$ propionic acid put the culture media up to $40^{\circ} \mathrm{C}$ add $0.59 \mathrm{gm}$ yeast in it by dissolving it in distilled water then sterilized it in the autoclave at 15 IP

Composition of Cardamom Oil (Bitter): Essential oil of Elettaria cardamom leaves was analyzed by GC-MS Sixteen components constituting $93.62 \%$ of the total ware identified The identified component were monoterpenes (27.37\%), oxygenated monoterpenes $63 \%$, acetates $(0.63)$ sesquiterpenes $(1: 43)$ and fatty acids caster $1.17 \%$ among this 4 terpineol 30.261 \& and $1: 8$ cenol $25,74 \%$ were found as major components where as other components were found to be a terpinene $(9,807 \%)$ p cymene $(5.300 \%)$ terpinene (4.6759) tujene (1633\%) la pinene (1.16596) sabinene $(2.069 \%)$ terpieness $(2.675 \%)$ linalool (2.6739) menth-2-en-1-01 0.754\%), terpanol (3:44\%) and endbory acetate $(0.593)$

Experimental set up: Take four culture vial, $1^{\text {st }}$ having $0.5 \mathrm{ul}$ cardamom oil and $10 \mathrm{gm}$ of normal culture

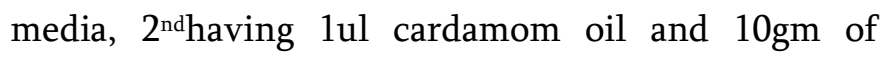

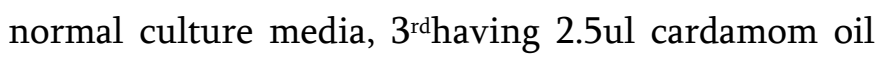

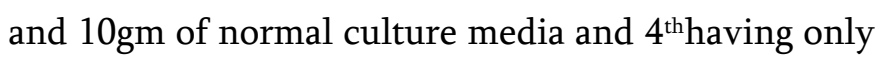
$10 \mathrm{gm}$ culture media without cardamom oil for normal growth of Drosophila melanogaster. Drosophila flies anaesthetized with diethyl ether and transfers into culture vial and each vial contains 10 lies ( 5 female and 5 male). The vial cover with cotton plug and place on the working table. The flies were laid eggs in culture, hatch and completed the life cycle within 10 to 15 days. Then collect the larval stages for measurement of total length and protein estimation by De Lowry's method. The measurement of the size of the various stages of Drosophila melanogaster was carried out with help of Oculometer. The total estimation of protein was done by the De' lowery method. Photographs were taken in the Carl Zeiss trinocular microscope and stereomicroscope. All results are presented as Mean \pm 
SD. Test of significance ( $t$-test) was used to analyse the data collected.

\section{RESULT AND DISCUSSION}

The size and growth in the control $D$. melanogaster are normal but in experimental $D$. melanogaster size and growth rate was slightly higher. In the micrometre, the change was $1.5 \mathrm{um}, 3.3 \mathrm{um}, 0.3 \mathrm{um}$, 2um, 0.5um, Oum of $1^{\text {st }}, 2^{\text {nd }}, 3^{\text {rd }}$ instar larvae,prepupa, pupa and adult respectively as compared to controlled D. melanogaster.

The protein concentration in control $D$. melanogaster is normal but in experimental $D$. melanogaster level of protein concentration was slightly higher. The change protein concentration was $0.7 \mathrm{ul}, 0.5 \mathrm{ul}, 0.34 \mathrm{ul}$, $0.11 \mathrm{ul}, 0.19 \mathrm{ul},-0.2 \mathrm{ul}$ of $1^{\text {st }}, 2^{\text {nd }}, 3^{\text {rd }}$ instar larvae, prepupa, pupa and adult respectively as compared to control D. melanogaster. In the present study we found that with the increased in concentrations the size of different development stages of Drosophila melanogaster were increased as compared to control. This increase in size may be result due to the effect of cardamom oil.

In other studies (Arslan et al. 2005; Al-Saleh et al. 2006). The higher bursa index observed in the chickens fed CEO-supplemented diets could be attributed to the antimicrobial and anti-inflammatory activities of active substances from cardamom, which may induce a positive effect in the activation and development of these organs. The inflammatory cytokines, IL-1b and IL-6, which are widely expressed in lymphoid tissue of birds, are the most powerful cognitive pathways in response to inflammatory processes.

Green cardamom supplement improved the grade of fatty liver, serum glucose indices, lipids, and irisin level among overweight or obese NAFLD patients. The changes in these biomarkers may yield beneficial effects on NAFLD (Daneshi-Maskooni et al., 2019).

Table No. 1 : Measurement of size and protein from various larval stages of Drosophila melanogaster.

\begin{tabular}{|c|c|c|c|c|c|}
\hline Sr. No. & \multirow{2}{*}{\begin{tabular}{c} 
Larval stage \\
\cline { 3 - 5 }
\end{tabular}} & \multicolumn{2}{|c|}{$\begin{array}{c}\text { Size of larval stage in } \\
\text { micrometer }(\mu \mathrm{m})\end{array}$} & \multicolumn{2}{|c|}{$\begin{array}{c}\text { Protein concentration larval stage in } \\
\text { microlitre }(\mu \mathrm{l})\end{array}$} \\
\cline { 3 - 6 } & & Control & Experimental & Control & Experimental \\
\hline 1 & $1^{\text {st }}$ instar & 40.5 & 42 & 0.238 & 0.245 \\
\hline 2 & $2^{\text {nd }}$ instar & 40.7 & 44 & 0.260 & 0.265 \\
\hline 3 & $3^{\text {rdinstar }}$ & 50.5 & 50.8 & 0.286 & 0.320 \\
\hline 4 & Prepupa & 60 & 62 & 0.364 & 0.375 \\
\hline 5 & Pupa & 74.5 & 75 & 0.421 & 0.440 \\
\hline 6 & Adult & 110 & 110 & 0.568 & 0.566 \\
\hline
\end{tabular}


Size of larval stage in micrometer $(\mu \mathrm{m})$

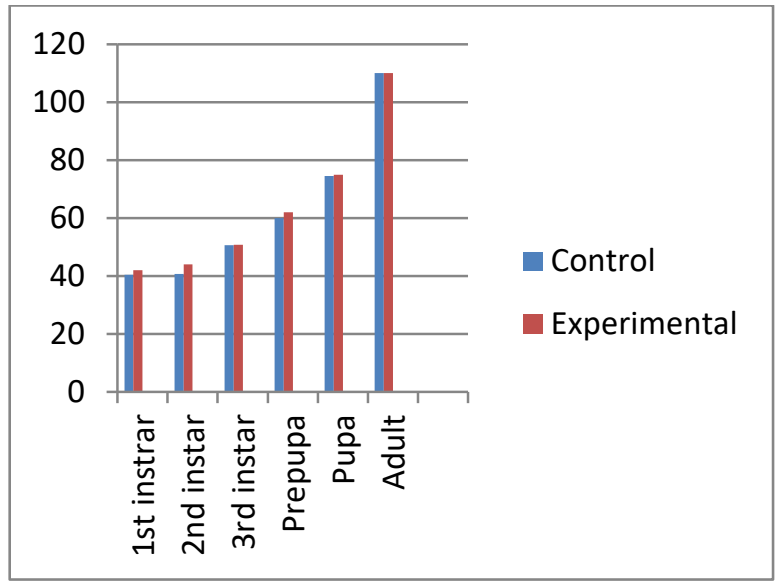

\section{First Instar Larvae}

Control

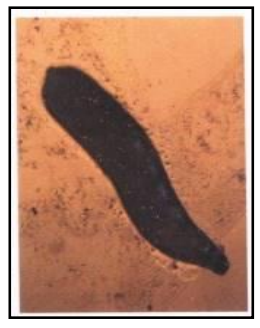

\section{Second Instar Larvae}

Control

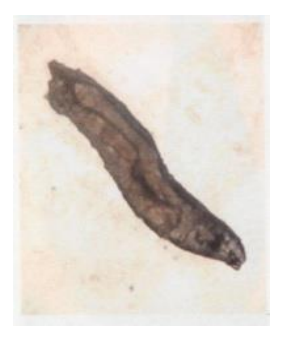

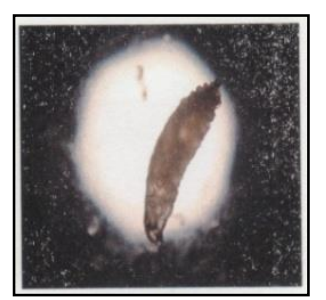

$0.5 \mu \mathrm{l}$

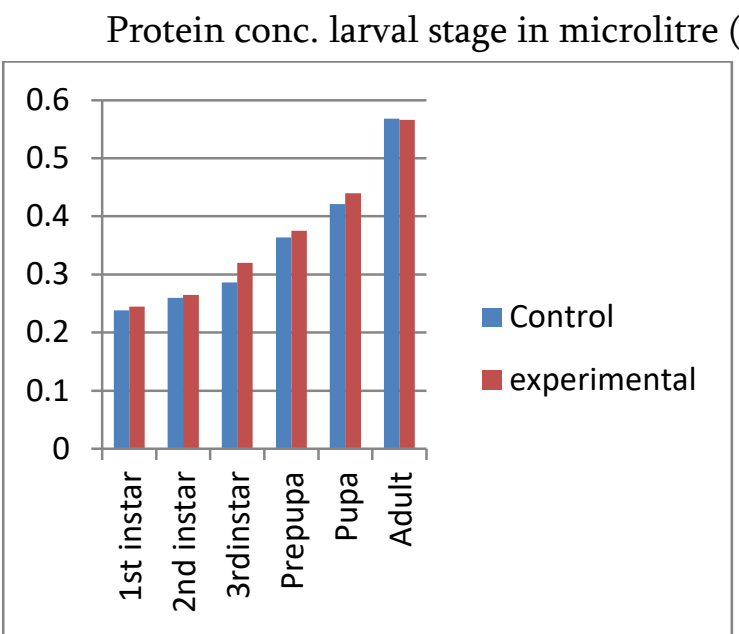

\section{Experimental}

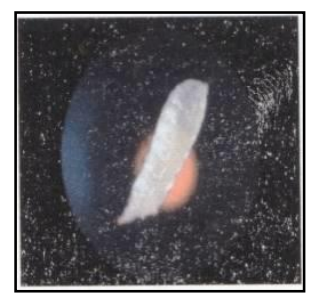

$1 \mu \mathrm{l}$

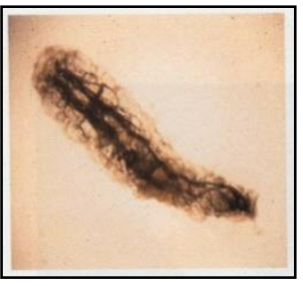

$2.5 \mu \mathrm{l}$

\section{Experimental}

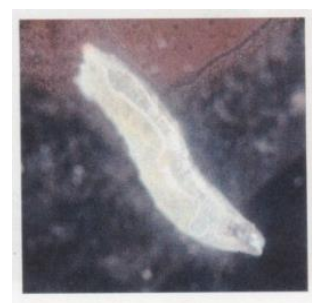

$0.5 \mu \mathrm{l}$

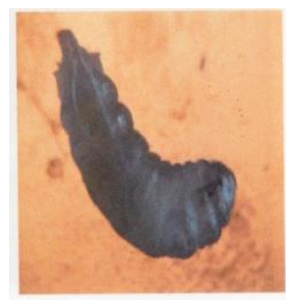

$1 \mu \mathrm{l}$

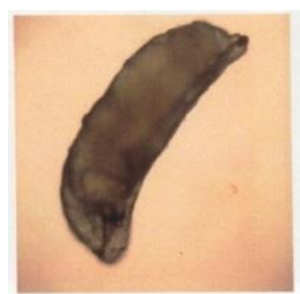

$2.5 \mu \mathrm{l}$

\section{Third Instar Larvae}

Control

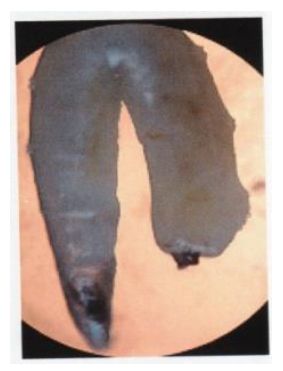

Experimental

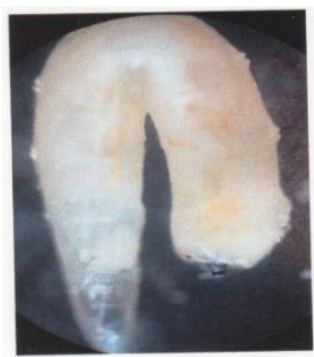

$1 \mu \mathrm{l}$
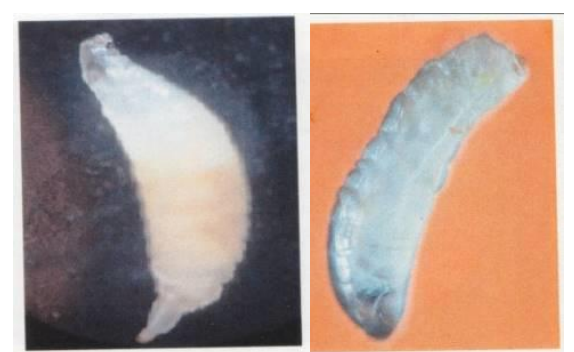

$2.5 \mu \mathrm{l}$ 


\section{Pre-pupa}

Control

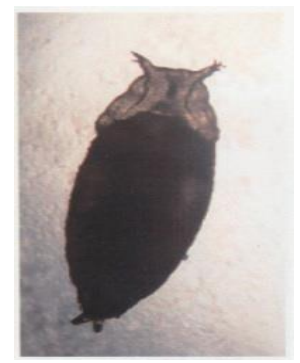

Pupa

\section{Control}

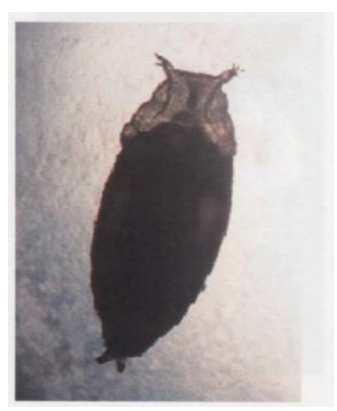

\section{Experimental}

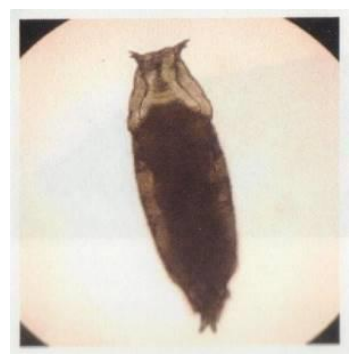

$0.5 \mu \mathrm{l}$

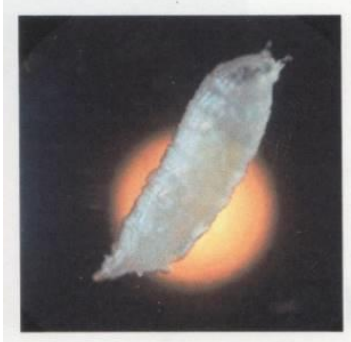

$1 \mu \mathrm{l}$

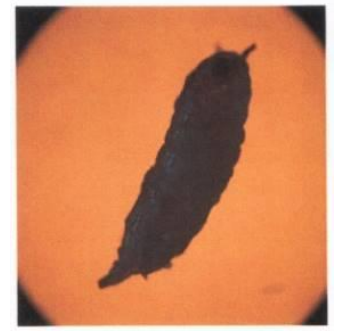

$2.5 \mu \mathrm{l}$

\section{Experimental}

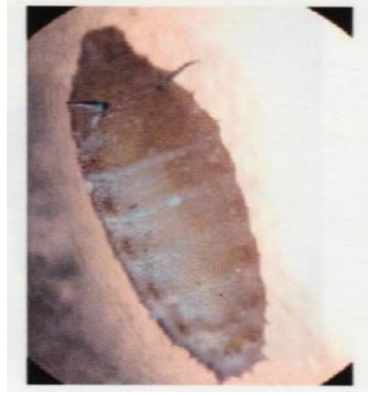

$0.5 \mu \mathrm{l}$

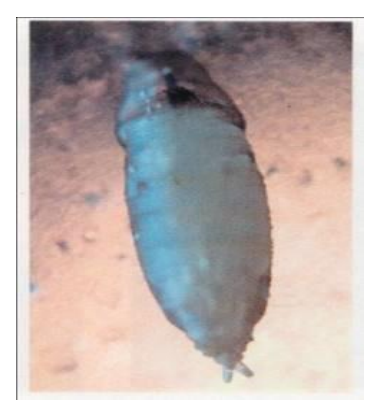

$1 \mu \mathrm{l}$

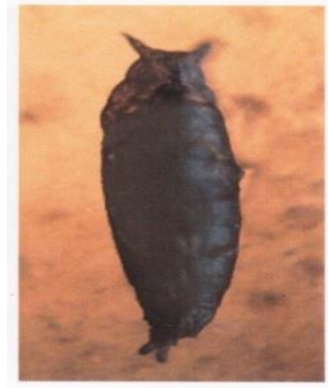

$2.5 \mu \mathrm{l}$

Adult

Control

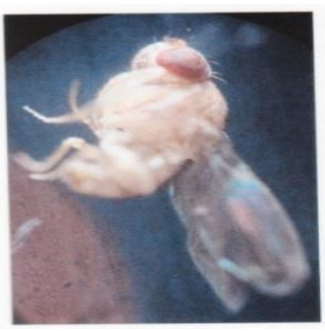

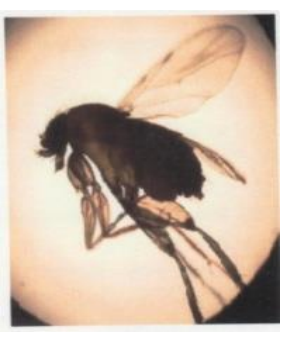

$0.5 \mu \mathrm{l}$

\section{Experimental}

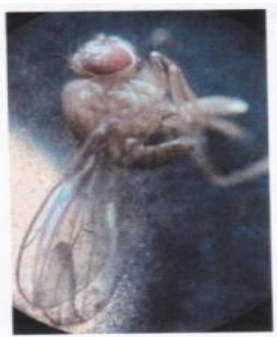

$1 \mu \mathrm{l}$

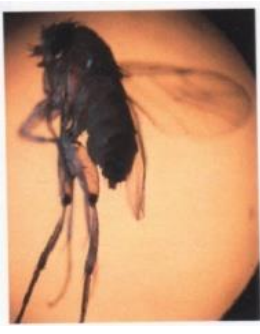

$2.5 \mu \mathrm{l}$
Laarif et al. (2013) reported the chemical composition and insecticidal activity of essential oil from (Citrus aurantium) (Rutaceae) fruit peels against two greenhouse insects such as Spodoptera littoralis (Noctuidae) and T. absoluta. Moawad et al. (2015) reported that mixed clove, bitter orange and zinc sulfate collectively had the ability to cause highest mortality to T. absoluta larvae to a degree of $97.0 \%$.
In another study, the insecticidal properties of essential oils extracted from Citrus aurantium were tested against third instar larvae of pest species, T. absoluta (Ebadah et al., 2016). LC50 values for 3rd larval instars (outside leaf and inside leaf) were 17.56 and $59.93 \mathrm{ml} / \mathrm{L}$ air, respectively. However, in recent studies, the LC50 values of cardamom essential oils in the leaves inside and outside of the larvae were 7.87 , 
$1.54 \mathrm{ml} / \mathrm{L}$ air, respectively. Hence, the essential oil of cardamom is more effective than that of orange. Moawad et al. (2013) stated that clove, eugenol and iso eugenol caused highly reduced percentage of penetration and accumulative mortality of larvae and caused ovipositional deterrence reaction toward adult stage of T. absoluta under laboratory conditions. In addition, Perez et al. (2013) evaluated the effect of different cinnamates on the behavior of larval herbivory of the second stage of $\mathrm{T}$. absoluta on tomato discs in different aqueous solutions of different concentration.

These results suggest that E. cardamomum oil has potential to be used in sustainable pest management in the greenhouse. It will purely safeguard the environment and health of the user especially when the application of synthetic insecticides gives rise to the development of resistance and pollution of the environment.

\section{REFERENCES}

[1]. Abbasipour H, Mahmoudvand M, Rastegar F, Hosseinpour MH. (2011b). Fumigant toxicity and oviposition deterrency of the essential oil from cardamom, Elettaria cardamomum, against three stored-product insects. J Insect Sci 11:165.

[2]. Al-Saleh et al. 2006 Al-Saleh, Grisellhi Billedo \& Innam I. EI-Doush (2006), levels of selenium, DL- $\alpha$-tocopherol, DL- $\Upsilon$ - tocopherol, all-transretional, thymoquinone and thymol in different brands of Nigella sativa seeds, Journal of Food Composition and Analysis, Vol. 19, Issues 2-3, March-May 2006, 167-175.

[3]. Al-Zuhair H, Al-Sayed B, Ameen HA, AlShoora H. (1996). Pharmacological studies of cardamom oil in animals. Pharmacol Res 34:7982.

[4]. Arslan1H. , O* zlem Kurt Azap1 *, O* nder Ergo"nu"1 2 and Funda Timurkaynak1 (2005)
Risk factors for ciprofloxacin resistance among Escherichia coli strains isolated from community-acquired urinary tract infections in Turkey, Journal of Antimicrobial Chemotherapy (2005) 56, 914-918.

[5]. Belmain SR, Neal GE, Ray DE, Golop P. (2001). Insecticidal and vertebrate toxicity associated with ethnobotanicals used as postharvest protectants in Ghana. Food Chem Toxicol 39:287-91.

[6]. Daneshi-Maskooni, M., Keshavarz, S. A., Qorbani, M., Mansouri, S., Alavian, S. M., Badri-Fariman, M. \& Sotoudeh, G. (2019). Green cardamom supplementation improves serum irisin, glucose indices, and lipid profiles in overweight or obese non-alcoholic fatty liver disease patients: a double-blind randomized placebo-controlled clinical trial. BMC complementary and alternative medicine, 19(1), 1-11.

[7]. Ebadah IM, Shalaby SEM, Moawad SS. (2016). Impact of certain natural plant oils and chemical insecticides against tomato insect pests. J Entomol 13:84-90.

[8]. Laarif A, Zarrad K, Tayeb W, et al. (2013). Chemical composition and insecticidal activity of essential oil from (Citrus aurantium) (Rutaceae) fruit peels against two greenhouse insects; Spodoptera littoralis (Noctuidae) and Tuta absoluta (Gelechiidae). Adv Agric Sci Eng Res 3:825-30.

[9]. Moawad SS, Ebadah IM, Mahmoud YA. (2013). Biological and histological studies on the efficacy of some botanical and commercial oils on Tuta absoluta Meyrick (Lepidoptera: Gelechiidae). Egypt. J Biol Pest Control 23:3018.

[10]. Moawad SS, Sharaby A, Ebadah IM, El-Behery H. (2015). Efficiency of zinc sulfate and some volatile oils on some insect pests of the tomato crop. Global Adv Res J Agric Sci 4:182-7. 
[11]. Nair KPP (2002) “The nutrient buffer power concept" - a revolutionary soil management technique for sustainable agriculture. Invitational research paper presented at the 17th world soil science congress. Bangkok, August, p 2002.

[12]. Perez ME, Haramboure M, Mirande L, et al. (2013). Biological activity of three Alkyl Cinnamates on young larvae of Tuta absoluta. Comm Appl Biol Sci 78:299-303.

[13]. Utta-Ur' R, Choudhary MI, Ahmed A, Iqbal MZ. (2000). Demirci B, Demirci F, Baser KHC. Antifungal activity and essential oil constituent of some spices from Pakistan. J Chem Soc Pakistan 22: 60-5.

\section{Cite this article as :}

Dr. Y. D. Akhare, H. A. Patharikar, "The Phenotypic Effect of Cardamom oil on the Developmental Stages of Drosophila Melanogaster", International Journal of Scientific Research in Science and Technology (IJSRST), Online ISSN : 2395-602X, Print ISSN : 23956011, Volume 8 Issue 5, pp. 225-231, SeptemberOctober 2021. Available at doi : https://doi.org/10.32628/IJSRST218534

Journal URL : https://ijsrst.com/IJSRST218534 